\section{Thousands of lives could be saved using tranexamic acid for patients with bleeding trauma}

A systematic review of randomised controlled trials of the effectiveness of tranexamic acid (TXA), which reduces clot breakdown, in patients with bleeding after severe injury shows that this inexpensive drug could save tens of thousands of lives a year. ${ }^{1}$ The review found that TXA reduces the risk of death in injured patients with severe bleeding by about $10 \%$ compared with giving no treatment. This would equate to more than 70000 lives a year if treatment were rolled out world wide (see table 1). On the basis of these new findings, the British military have already started using TXA to treat soldiers wounded in battle in Afghanistan, ${ }^{2}$ and TXA is now being incorporated into civilian trauma treatment protocols around the world. ${ }^{3}$

Most of the data in the review came from the international CRASH-2 trial, ${ }^{4}$ which recruited 20211 patients with bleeding trauma from some 40 countries world wide and showed that TXA significantly reduces mortality with no apparent increase in the risk of vascular occlusive events. Because the CRASH-2 results are based on large numbers of patients, with both blunt

Table 1 Deaths that could be avoided by the administration of tranexamic acid (TXA) to patients with bleeding trauma (10 countries with the highest numbers of avoided deaths shown) ${ }^{1}$

\begin{tabular}{lccc}
\hline Country & $\begin{array}{l}\text { Trauma } \\
\text { deaths }\end{array}$ & $\begin{array}{l}\text { Haemorrhage } \\
\text { deaths }\end{array}$ & $\begin{array}{l}\text { Deaths averted } \\
\text { with TXA }\end{array}$ \\
\hline India & 714730 & 85768 & 12865 \\
China & 667277 & 80073 & 12011 \\
Indonesia & 279499 & 33534 & 5030 \\
Russia & 246836 & 29620 & 4443 \\
Brazil & 122953 & 14754 & 2206 \\
USA & 122529 & 14703 & 2206 \\
Iraq & 99968 & 11996 & 1799 \\
Nigeria & 87811 & 10537 & 1581 \\
Bangladesh & 76938 & 9233 & 1385 \\
DRC & 73579 & 8829 & 1324 \\
World & 4100645 & 492077 & 73812
\end{tabular}

Copyright Cochrane Collaboration, reproduced with permission.

Trauma and haemorrhage death estimates taken from the WHO Global Burden of Disease Study: http://www.who.int/healthinfo/global_burden_disease/en/. and penetrating trauma, and from many different countries, they can be generalised widely. Given the high quality of evidence for the benefits of this drug, the authors recommend that TXA is considered for use in every patient with severe bleeding from traumatic injury.

Studies are now underway to see if TXA can reduce deaths from post partum haemorrhage ${ }^{5}$ (which kills about 100000 women each year, most of whom live in developing countries) and traumatic intracranial bleeding which is a major cause of death and disability. Further interactive material on the topic is available through the Cochrane Journal Club. ${ }^{6}$

The review mentioned here is published on the Cochrane Library (http://www.thecochranelibrary.com/) website. For further information on this or other Cochrane reviews contact Emma Sydenham, managing editor of the Cochrane Injuries Group (emma.sydenham@lshtm.ac.uk).

\section{Emma Sydenham}

Correspondence to Emma Sydenham, Cochrane Injuries Group, London School of Hygiene \& Tropical Medicine, Keppel Street, London WC1E 7HT, UK; emma.sydenham@lshtm.ac.uk

Competing interests None.

Provenance and peer review Not commissioned; internally peer reviewed.

Published Online First 5 May 2011

Injury Prevention 2011;17:211. doi:10.1136/injuryprev-2011-040059

\section{REFERENCES}

1. Roberts I, Shakur H, Ker K, et al. Antifibrinolytic drugs for acute traumatic injury. Cochrane Database Syst Rev 2011;(1):CD004896.

2. Sadler C. Injured soldiers in Afghanistan saved by blood clotting drug. British Forces News 20 Jan 2011. http://www.bfbs.com/news/afghanistan/injured-soldiersafghanistan-saved-blood-clotting-drug-43115.html (accessed 31 Mar 2011).

3. World Health Organization, Department of Reproductive Health and Research. Who Guidelines for the Management of Postpartum Haemorrhage and Retained Placenta. Geneva, Switzerland: WHO Press, 2009.

4. Shakur H, Roberts I, Bautista R, et al; CRASH-2 trial collaborators. Effects of tranexamic acid on death, vascular occlusive events, and blood transfusion in trauma patients with significant haemorrhage (CRASH-2): a randomised, placebo-controlled trial. Lancet 2010;376:23-32.

5. Shakur H, Elbourne D, Gülmezoglu M, et al. The WOMAN Trial (World Maternal Antifibrinolytic Trial): tranexamic acid for the treatment of postpartum haemorrhage: an international randomised, double blind placebo controlled trial. Trials 2010;11:40.

6. Antifibrinolytic drugs for acute traumatic injury. Cochrane Journal Club Issue 18. http:// www.cochranejournalclub.com/antifibrinolytic-drugs-acute-traumatic-injury-clinical/ (accessed 31 Mar 2011). 